\title{
¿Crisis o transición? \\ Caracterizaciones intelectuales. Del dualismo argentino en la apertura democrática ${ }^{1}$
}

\author{
Sergio E. Visacovsky² y Rosana Guber \\ Instituto de Desarrollo Económico y Social, Buenos Aires
}

Este trabajo presenta un análisis de la organización conceptual del modelo de "transición a la democracia" mediante el cual un amplio sector de científicos sociales conceptualizó la crisis de la última dictadura militar en la Argentina en 1982, e interpretaron su advenimiento y desenlace, para guiar a la sociedad hacia su definitiva democratización. Este modelo estaba sustentado en nociones y estructuras conceptuales producidas y empleadas en la sociedad argentina para describir e interpretar el proceso político. La noción de "crisis" revirtió en una aplicación del modelo de transición a la democracia que, aún cuando se propuso como un marco interpretativo volcado a la inauguración de una nueva era y a la superación definitiva de las interrupciones democráticas, conllevó una perspectiva sobre el pasado político y, en especial, sobre las causas del "autoritarismo", que se forjó dentro de los moldes clásicos del pensamiento argentino.

PAlABRAs Claves: crisis, transición democrática, Argentina, dualismo, cultura, intelectuales.

This article presents an analysis of the conceptual organization of the "democratic transition" model, through which an important sector of social scientists represented the military dictatorship crisis in Argentina in 1982, and interpreted its advent and ending, to guide the society towards its definitive democratization. This model was based on ideas and conceptual structures produced and used in the Argentine society to describe and to interpret the political process. We will explain that the notion of "crisis" was replaced for the democratic transition model; this paradigm was made according to the classic frames of Argentine thinking, and for this reason it was not only an interpretative frame to the inauguration of a new era and the final overcoming of the democratic instability, but also a perspective on political past and the causes of "authoritarianism".

KEYWORDS: crisis, democratic transition, Argentina, dualism, culture, intellectuals.

1 Este trabajo está basado en los resultados preliminares de varios proyectos de investigación; UBACyT TL57: "Usos del pasado e identidad social en la Argentina contemporánea: etnografías de las memorias sobre el 'Proceso de Reorganización Nacional (1976/1983)', Programación Científica 19982000 y el UBACyT F802. El presente trabajo constituye una reelaboración. Deseamos agradecer los comentarios críticos y sugerencias recibidos de Antonius Robben, José Emilio Burucúa, Federico Neiburg, Eduardo Hourcade, Cecilia Lesgart, Claudio Lomnitz y Mariano Plotkin.

2 Departamento de Ciencias Antropológicas, Universidad de Buenos Aires, Argentina. Centro de Antropología Social, Instituto de Desarrollo Económico y Social (IDES), Buenos Aires, Argentina.

3 CONICET-IDES, Centro de Antropología Social, Instituto de Desarrollo Económico y Social (IDES), Buenos Aires, Argentina. 
La derrota en las Islas Malvinas (Falklands) marcó un hito en la vida institucional argentina: puso fin a la última dictadura militar y a una sucesión casi ininterrumpida de democracias, semidemocracias y dictaduras desde 1930; terminó con una práctica oficial, sistemática y generalizada de desaparición, tortura, delación y muerte de personas; y concluyó el único conflicto bélico internacional del siglo XX que tuvo a la República Argentina como principal protagonista. El período que sucedió a la rendición argentina dio lugar a una prolífica literatura especializada de politólogos, sociólogos y filósofos, que calificó a la coyuntura como una "crisis" y que se abocó a la reflexión sobre las vías para superarla. Este campo, nuevo para la Argentina, adoptó el nombre de "transición a la democracia", "democratización de la sociedad argentina" y "pasaje del autoritarismo a la democracia", y constituyó un sitio específico desde el cual estos intelectuales de las ciencias sociales en la Argentina se convirtieron en expertos sobre la política, la sociedad y la cultura.

En estas páginas presentamos un análisis de la organización conceptual del modelo de "transición a la democracia" con que estos especialistas conceptualizaron la crisis de la dictadura militar autodenominada "Proceso de Reorganización Nacional" (en adelante PRN), e interpretaron su advenimiento y desenlace, para guiar a la sociedad argentina hacia su definitiva democratización. La vigencia de este modelo referido a hechos cronológicamente lejanos reside, como trataremos de mostrar aquí, en su anclaje en nociones y organizaciones conceptuales producidas y empleadas en la sociedad argentina para describir e interpretar el proceso político. Tal es el caso del reiterado recurso a la noción de "cultura" para caracterizar la política nacional, establecer las causas de sus males y proveer sus soluciones dentro de un marco interpretativo que llamaremos "dualista". Como los marcos de significaciones de los que hablaba Clifford Geertz, este dualismo comparte las características de las teodiceas y otros sistemas cosmovisionales en que es invocado, a la vez, como instrumento de diagnóstico y como aspecto de la realidad diagnosticada. En este sentido, la noción de "transición democrática" ha sido, también en términos de Geertz, un "modelo de" la realidad y un "modelo para" incidir en lo real. Su interés radica no sólo en su organización teórica, su gran difusión y la grave época que caracterizó y de la que fue parte, sino también en que intentó producir un cambio en el modo de sucesión de los acontecimientos y en su conceptualización como objeto de análisis. 
La crisis, entendida como irrupción abrupta, catástrofe, caída o puerta al nuevo orden, ${ }^{4}$ ha constituido una vía de acceso a la realidad sociopolítica argentina, un pasaporte a la autoridad de los analistas y un campo para la constitución de expertos. Pero desde 1982, quienes predicaron el modelo de la transición democrática aspiraban no sólo a interpretar sino también a impactar en la realidad política, terminando de una vez por todas con el decurso pendular entre dictaduras y democracias que acompañó al siglo XX argentino. ¿Por qué se concibió a la coyuntura abierta en 1982 como una "crisis" y como una "transición"? ¿Acaso ambos conceptos son compatibles en el imaginario político de este país? ¿Qué novedades introdujo su articulación y cuáles fueron sus limitaciones para entender la sociedad y la política argentinas? ¿Qué efectos de temporalidad suscitó para pensar su pasado y su futuro?

Como veremos aquí, la noción de "crisis" revirtió en una aplicación del modelo de transición a la democracia que, aun cuando se propuso como un marco interpretativo volcado a la inauguración de una nueva era y a la superación definitiva de las irrupciones institucionales argentinas, conllevó una perspectiva sobre el pasado político y, en especial, sobre las causas del "autoritarismo", que se forjó dentro de los moldes clásicos del pensamiento argentino. Estos moldes encuentran en "la crisis" más que en "la transición" un anclaje interpretativo de sustento dualista no sólo extremadamente familiar a los modelos historiográficos y políticos de este país, sino también promotor de ciertos objetos de investigación, y obturador de otros.

\section{Entre la política y la academia}

Una vez culminada la última dictadura militar, los textos producidos por intelectuales ligados a las ciencias sociales y a las humanidades argentina presentan el advenimiento democrático de 1983 con la expectativa de constituir un punto y aparte respecto de un pasado autoritario, plagado de turbulentos enfrentamientos y signado por la violencia política. Pero esta perspectiva no era sólo académica. La esgrimió en su plataforma electoral el radical Raúl Alfonsín que, tras ganar la contienda del 30 de octubre de 1983 que concluyó con el régimen del autodenominado "Proceso de Re-

4 Para una discusión sobre los usos de la noción de "crisis" por las ciencias sociales y las prácticas políticas y económicas en el siglo XX, véase: Holton, Robert J.: "The idea of crisis in modern society", en British Journal of Sociology 38, 1987, págs. 502-520. 
organización Nacional" (en adelante PRN), ${ }^{5}$ se dispuso a erradicar el endémico autoritarismo y a fundar una nueva "cultura política". Como afirmó tiempo después, en 1984, ya como presidente de la Nación, "la debilidad de la democracia en la Argentina... (y la fugacidad de sus intentos) radican menos en sus instituciones que en nuestro modo subjetivo de asumirlas. Se trata de un problema cultural más que institucional". ${ }^{6}$ Según él, una nueva lógica y una nueva legitimidad podían elaborarse desde fuera de su contexto histórico, "educando" a las subjetividades en esa nueva cultura. Desde su asunción el 10 de diciembre de 1983, el partido gobernante transformó a la "democracia" en el leit-motif de su gestión, viabilizadora de una "cultura constitucional" que desplazaría "para siempre" a la cultura autoritaria de los golpes de estado.

Como en otros momentos considerados críticos de la Argentina, diversos intelectuales y políticos señalaron la necesidad de una profunda y definitiva transformación de la sociedad. El final del PRN se presentaba como una nueva oportunidad para que la nación se encausara por la buena senda. Si en tiempos anteriores para salir de la crisis era necesaria la "modernización", el "desarrollo" o la "revolución", en los años 1980 el nuevo principio orientador del cambio social —o, más propiamente, cultural— era la "democratización". Esto no implicaba que se hubiesen abandonado convicciones tales como "desarrollar" el aparato productivo, "modernizar" la tecnología o generar condiciones más equitativas en la distribución del ingreso, pero todos estos temas no podían materializarse a menos que la Argentina se realizase, de una vez y para siempre, como democracia.

Los abogados de esta postura afirmaban que el país había vivido durante el pasado reciente - $\mathrm{y}$ en varios puntos del siglo $\mathrm{XX}$ - en el auto-

5 Aquí empleamos preferentemente el término "Proceso de Reorganización Nacional", entre comillas o más a menudo abreviado (PRN), para designar el modo nativo de autodefinición del gobierno militar asumido en 1976. Véase: Robben, Antonius C.G.M.: "The Fear of Indifference: Combatants'Anxieties about the Political Identity of Civilians during Argentina's Dirty War", en Koonings, Kees y Dirk Kruijt (coord.): Societies of Fear: The Legacy of Civil War, Violence and Terror in Latin America, Zed Books, Londres, 1999, pág. 139, nuestra traducción. Visacovsky, Sergio Eduardo: El Lanús Memoria y política en la construcción de una tradición psiquiátrica y psicoanalítica argentina, Alianza Editorial, Buenos Aires, 2002; Visacovsky, Sergio Eduardo: "Entre lo evidentemente sucedido y lo posiblemente experimentado: para una reconciliación entre historia, memoria social y análisis narrativo", en Entrepasados, Revista de Historia, Año XIII, N. . 26, 2004, págs. 127-145.

6 “Alfonsín” en López, Ernesto: El último levantamiento, Editorial Legasa, Buenos Aires, 1988, pág. 57. Nuestro paréntesis. También Hipólito Solari Yrigoyen parangonaba la naciente democracia con una criatura recién nacida, lo cual explicaba su debilidad. Véase: Solari Yrigoyen, Hipólito: "Antidemocracia y democracia en la Argentina", en Sosnowski, Saúl (comp.): Represión y reconstrucción de una cultura: el caso argentino, Eudeba, Buenos Aires, 1988, págs. 19-26. 
ritarismo. El uso de la violencia como recurso político en lugar de la discusión, el pacto y la negociación, las violaciones a los derechos humanos como consecuencia del terrorismo de estado durante el PRN, incluso las tendencias de organización social corporativas o las lealtades a liderazgos carismáticos, eran expresiones del autoritarismo argentino, el cual había establecido una recurrente inestabilidad del sistema republicano. Esta experiencia de crisis permanente se contraponía a la democracia, la cual, sin embargo, no era completamente extraña al país; es sólo que al coexistir en una relación de oposición y conflicto con el autoritarismo, había sucumbido a él. La Argentina se encontraba atrapada en el presente, y desde hacía muchas décadas, en el dilema que le proponía esta dualidad inherente a su propia condición, autoritarismo/democracia, en una sucesión crítica y por lo tanto tumultuosa, pasional, impulsiva e incierta. Dada la magnitud del horror generado por la violencia política y el terrorismo de estado en los años 1970, las horas cruciales que siguieron a la derrota de Malvinas y al triunfo de Alfonsín, podían resolverse sólo con la disolución del autoritarismo y la instauración definitiva de la democracia.

Sin embargo, pese a las horas decisivas que vivía la Argentina, el ingreso a la democracia no podía producirse de la noche a la mañana. Aunque imperioso, el cambio demandaba tiempo no sólo por el arraigo del autoritarismo en la sociedad, sino porque la transformación debía imponerse de un modo gradual, consensual y democrático para no contradecir los preceptos rectores de la democratización, y para instaurar esa nueva cultura en la política y en la sociedad. Precisamente, al centrar su atención teórica en la "transición", los expertos ponían de manifiesto sus sospechas de que los cambios eleccionarios, por sí mismos, garantizasen la estabilidad democrática e, implícitamente, la salida de una "cultura política autoritaria" y la "crisis" que había provocado. Hablar de "transición democrática" refería a la teoría de la democratización y a un período histórico determinado. En la Argentina, la "transición democrática" se convirtió en un período de incierta duración, ${ }^{7}$ abierto en las postrimerías del PRN, señalado

7 El período que abarcó la "transición" es difícil de precisar, toda vez que los autores se contradicen tanto en sus comienzos como en su finalización. Algunos la ubican en el período inmediatamente anterior al arribo al poder de Raúl Alfonsín, y a partir del fin de la Guerra de Malvinas (19821983). Otros, sin embargo, la extienden más allá, diferenciando el funcionamiento de las instituciones democráticas, de la democratización efectiva de la sociedad. Por otra parte, las continuas referencias de políticos e intelectuales respecto del carácter "débil" y "frágil" de la novel democracia refuerzan aún más esta última interpretación. 
como un tiempo real parte de la periodización usual de la historia política argentina contemporánea. ${ }^{8}$

Como los ritos de paso estudiados por los antropólogos, ${ }^{9}$ también la "transición democrática" argentina trataba de tender un puente entre un presente crítico (caracterizado por el autoritarismo), que se necesitaba abandonar (y, por ello, transformar en pasado), y un futuro estable (la democracia) al que se deseaba arribar (y, por ende, transmutar en presente efectivo). La Argentina ingresaba así a un tiempo liminal en el que todo era transitorio $^{10}$ e incierto. Lo que había definido a la nación hasta entonces debía ser abandonado, y lo que se esperaba que la definiese aún no había nacido o estaba débilmente instaurado.

El fin de la transición debía acontecer —o ya estaba acaeciendo- en un lapso que se esperaba fuese breve para democratizar definitivamente a la sociedad argentina, una vez "restaurada", "recuperada" o "restituida" la democracia institucional. Pero para que esta operación de democratización fuese eficazmente transformadora, había que impedir que el autoritarismo retornase, como tantas veces había ocurrido. ¿Qué garantías podía tener la novel democracia y el proyecto democratizador de la sociedad para que el ciclo fatídico no volviera a imponerse? ¿Cómo desarmar la alternancia entre autoritarismo y democracia que había comandado hasta entonces la historia política nacional?

En modo análogo a las teodiceas religiosas, ${ }^{11}$ el desafío interpretativo y práctico que se les planteaba a los expertos de la transición era explicar, primero, cómo había sido posible un régimen que, como ningún otro en el siglo XX, había basado su existencia en el terror, y segundo, cómo había sido posible además el eterno péndulo argentino entre regímenes "democráticos" y "autoritarios". Mostraremos aquí que la formulación de esta

8 En este modo es empleado por autores como Landi, Oscar: "Cultura y política en la transición democrática”, en Oszlak, Oscar: 'Proceso', crisis y transición democrática, Centro Editor de América Latina, Buenos Aires, 1984, pág. 102-123; Nun, José y Portantiero, Juan Carlos (coord.): Ensayos sobre la transición democrática en la Argentina, Editorial Puntosur, Buenos Aires, 1987

9 Véase: Van Gennep, Arnold: The Rites of Passage, University of Chicago Press, Chicago, 1960; Turner, Victor W.: The Ritual Process, University Press, Ithaca, Cornell, 1969.

10 Turner: The Ritual..., pág. 95.

11 Véase el concepto de teodicea en: Weber, Max: Sociología de la religión, Ediciones Coyoacán, México, 1997, págs. 191-198. También, su uso ampliado como "teodicea secular" en: Herzfeld, Michael: The Social Production of Indifference: Exploring the Symbolic Roots of Western Bureaucracy, University of Chicago Press, Chicago, 1993, pág. 564, nuestra traducción. 
narrativa del pasado nacional ${ }^{12}$ estuvo fundada en un principio de organización dualista ${ }^{13}$ antagónico, el cual interpretaba, diagnosticaba e incidía sobre un Estado considerado crónicamente como "crítico" de la República. Como veremos seguidamente, las representaciones de los intelectuales argentinos de la salida del gobierno militar están organizadas en modo semejante a los dualismos antagónicos que, basados en el principio de jerarquía entre opuestos y faltos de la posibilidad lógica de la complementariedad, sólo dan lugar a la dominación de un término sobre el otro. El dualismo al que nos referimos supone la división del mundo entre principios opuestos y enemigos, cuya lucha se despliega a lo largo de la Historia, siguiendo un patrón cíclico, pues cada fuerza en pugna obtiene victorias transitorias. El problema que se presenta es, entonces, cómo lograr que la dominación actual de uno de los antagonistas (en lo posible, el democrático) no se invierta en el futuro. Este planteo tiene algunas consecuencias, pues la única salida posible del dualismo antagonista es su transformación en monismo. Pero como los principios actuantes son igualmente potentes, las dos fuerzas no consiguen vencerse; por eso aspiran a que la eterna contienda se resuelva en un combate final. Mientras tanto, los momentos victoriosos exigen el control de todas las manifestaciones del oponente, para lo cual es preciso identificarlo, desenmascararlo y discriminarlo/separarlo. $\mathrm{Si}$ todos los eventos, personajes e instituciones pasadas y presentes admiten una y sólo una clasificación en algunas de las dos clases posibles, no sólo se resuelve el problema de la identificación del contrario, sino que es posible determinar, además, las líneas de parentesco genealógico que vinculen formas autoritarias o democráticas del presente con las del pasado. Así, el pasado vive en el presente para inclinar la balanza hacia uno u otro lado, en condiciones de crisis actuante o pendiente.

El programa de democratización que imaginaron los intelectuales de la transición y que intentó ejecutar el gobierno radical se abocó a buscar los núcleos "puros", "incontaminados", "resguardados", en definitiva, "democráticos" en los que fuera posible confiar, con el fin de construir a partir de

12 Sobre narrativas de crisis, véase : Hay, Colin: "Rethinking Crisis: Narratives of the New Right and Constructions of Crisis", en Rethinking Marxism, 8/2, 1995/6, págs. 2-18; "Narrating Crisis: The Discursive Construction of the Winter of Discontent", Sociology 30, 1996, págs. 253-277; "From Crisis to Catastrophe? The Ecological Pathologies of the Liberal-Democratic State Form", en Innovation: The European Journal of Social Sciences 9, 4, 1997, págs. 421-435.

13 Véase : Durkheim, Emile y Marcel Mauss: "De quelques formes primitives de classification”, en Mauss, Marcel : Oeuvres, v.2, Minuit, Paris, 1969. 
ellos una nueva sociedad; entre tanto, arremetía contra los núcleos "impuros" y "contaminados" de autoritarismo.

\section{“Crisis" coyuntural y "crisis" esencial}

Tal vez uno de los acuerdos más profundos y persistentes gestados por los intelectuales y expertos de la "transición" ha sido el de la "recuperación de" o el "retorno a" la democracia como consecuencia de una "crisis" interna en el gobierno tras la derrota militar por Gran Bretaña en las Islas Malvinas. ${ }^{14}$ Según este relato, la rendición ante las fuerzas británicas el 14 de junio ocasionó el alejamiento de la presidencia del General Leopoldo F. Galtieri en medio de una profunda convulsión en el ámbito castrense, entendiendo por "crisis" la descomposición, la caída de la confianza internacional, el descontrol y la pérdida de autoridad interna. El 23 de junio la Fuerza Aérea y la Marina se apartaron del comando del PRN, y dejaron que el Ejército asumiera la conducción política. El 1 de julio el Estado Mayor Conjunto designó al General Reynaldo Bignone como nuevo titular del Poder Ejecutivo y proclamó la decisión de "institucionalizar la Nación en el menor tiempo que sea posible".

En este proceso, los partidos políticos ejercieron su presión. Integrada por radicales, peronistas, desarrollistas, intransigentes y demócratas cristianos en 1981 para negociar una salida electoral con el segundo presidente militar, Roberto Viola, la "Asamblea Multipartidaria" convocó el 16 de diciembre de 1982 una manifestación que reunió a unas 100.000 personas. La respuesta del gobierno fue una brutal represión, en la que hubo un muerto, varios heridos y un centenar de detenidos. Como corolario, la "Multipartidaria" exigió al gobierno un cronograma para la normalización institucional y respuestas oficiales por los ciudadanos desaparecidos y la derrota militar del Atlántico Sur. Bignone anunció la decisión del gobierno de llamar a elecciones en 1983. Así, se abría el período "de transición a la democracia", cerrando y consagrando una secuencia que se expresaba en algunos productos intelectuales de la época, como los dos volúmenes compilados por Oscar Oszlak, Proceso, crisis y transición democrática..$^{15}$

14 Solari Yrigoyen: "Antidemocracia y democracia..."; Villarreal, Juan: "Los hilos sociales del poder", en Crisis de la dictadura argentina. Política económica y cambio social 1976-1983, Siglo XXI, Buenos Aires, 1985, págs. 201-283.

15 Oszlak, Oscar: 'Proceso', crisis..., págs. 7-17. 
Si bien esta crisis de coyuntura era responsabilidad del régimen militar, por lo que podía encontrar su salida con el llamado a elecciones y la asunción de las nuevas autoridades, los intelectuales de la "transición democrática" detectaban una crisis más profunda que no era patrimonio de una coyuntura o de un régimen, sino de la nación toda. En otros términos: una cosa era buscar una solución a la crisis política del PRN, y otra encontrar una salida para la crisis en que estaba la Argentina desde hacía décadas. El término "crisis" era la síntesis de términos negativos tales como "deterioro", "fragmentación", "desarticulación" e "inestabilidad", aplicados al "Estado", al "sistema político" o a la "cultura". ${ }^{16}$ Por eso, la "transición democrática" significaba salir de la crisis, esto es, "reorganización", "recomposición", "reparación", "reunificación" o "reestructuración" del "Estado", el "sistema político" o la "cultura". Estas ideas eran compartidas por sectores intelectuales que podían albergar simpatías políticas muy distintas. Por ejemplo, la asociación entre "crisis" y "descomposición general de la sociedad" estaba presente en los intelectuales cercanos por entonces al peronismo, como el filósofo José Pablo Feinmann, que por esa vía explicaba el advenimiento del PRN. ${ }^{17}$

Por su parte, el término "crisis" como "desestructuración" y "fragmentación" era empleado para señalar los efectos del PRN en la sociedad, o en algunos de sus grupos. Así, desde una perspectiva del poder inspirada en Michel Foucault, complementada con el concepto de hegemonía de Antonio Gramsci, Juan Villarreal, otro intelectual ligado al peronismo, sostenía que la política del PRN había conducido a un panorama de "desestructuración/reestructuración", en la medida que fracturó los sectores populares e intentó, por medio del terror, generar nuevas formas de relación social. Estos efectos, que él llamó "crisis orgánica", ${ }^{18}$ dieron lugar a un "proceso social regresivo", resultante no sólo de la obra de los militares, sino de una conjugación más compleja de fuerzas sociales, entre las cuales participó la corporación militar. Fuerzas políticas, religiosas y culturales se plantaron como reacción frente a los avances y a la radicalización de los sectores populares en las décadas pasadas. ${ }^{19}$ 1982.

16 Landi, Oscar: Crisis y lenguaje político, vol. 4, Nro. 4, Estudios CEDES, Buenos Aires,

17 Feinman, José Pablo: "Política y verdad. La constructividad del poder", en Sosnowski, Saúl (comp.): Represión y reconstrucción de una cultura: el caso argentino, Eudeba, Buenos Aires, 1988, págs. 79-94.

18 Villarreal: Los hilos ... pág. 208.

19 Villarreal: Los hilos ... pág. 215. 
Desde la crítica literaria, Beatriz Sarlo (directora de la revista Punto de Vista y por entonces miembro del "Club Socialista", ambos en sus comienzos adherentes a la propuesta alfonsinista) aplicaba la imagen de la fragmentación al campo intelectual, apelando al término "fractura" que, según ella, había sido doble: una provocada por los exilios, que había dividido al campo entre "los de adentro" y "los de afuera", atomizándolos; y otra que los había segregado de los espacios públicos y de los sectores populares, a diferencia de lo que había ocurrido en los años 1960 y el primer lustro de los $1970 .{ }^{20}$ La represión desatada por la dictadura había conducido al "corte" del tejido social, como medio de desalentar el disenso y la resistencia, e imponer la despolitización a todos los niveles, apelando a la defensa de modelos individuales y familiares, y estigmatizando a los intelectuales como subversivos y responsables disolventes de la sociedad. ${ }^{21}$

Desde la renovación política e intelectual del peronismo tras su primera derrota electoral en 1983, el filósofo Oscar Landi relacionaba la "crisis" con la "fragmentación" del campo intelectual, entendida como "desarticulación de sus posibles principios de organización internos". ${ }^{22}$ En términos semejantes a Villarreal y Sarlo, Landi sostenía también que el PRN se había propuesto "fragmentar" el tejido social a través del miedo y producir nuevas mentalidades centradas en "el mercado". ${ }^{23}$ No obstante, la acción del PRN se desarrollaba en un terreno ya desarticulado por la misma inestabilidad política que impedía tanto la continuidad y consolidación de corrientes de pensamiento como el fortalecimiento de las instituciones, entre ellas las "culturales". ${ }^{24}$

Así, en 1982, la Argentina vivía una crisis que era en parte heredada del PRN, y en parte permanente, hasta explicativa del PRN. La transición a la democracia debía conducir al abandono de la "crisis" coyuntural y de la esencial, esto es, a la supresión de la inestabilidad política, la reparación de lo deteriorado o destruido, y la reorganización o reestructuración de lo desorganizado o desestructurado. Pero para lograr tal objetivo era menester no sólo dar cuenta de la aparición del PRN, sino situarlo en un cuadro más amplio que lo incluyese en la lógica de la inestabilidad política, y que per-

20 Sarlo, Beatriz: "El campo intelectual: un espacio doblemente fracturado", en Sosnowski, Saúl (comp.): Represión y reconstrucción de una cultura: el caso argentino, Eudeba, Buenos Aires, 1988, págs. 95-107.

21 Sarlo: "El campo intelectual...", pág. 103.

22 Landi: Crisis ... pág. 104.

23 Ibídem, pág. 109.

24 Ibídem, pág. 107. 
mitiera entender las razones que lo condujeron a desarrollar acciones destructivas inéditas. Se necesitaba, en suma, formular una teodicea secular.

\section{La batalla entre el "autoritarismo" y la "democracia"}

La polarización medular de los "nuevos tiempos" en la Argentina de comienzos de los 1980, autoritarismo/democracia, y el modelo de la "transición democrática" no fueron aplicados con exclusividad a la Argentina. También se usaron para interpretar y producir políticas en países de Europa (España, Portugal, Grecia) y Latinoamérica (Brasil, Uruguay y Chile). Cecilia Lesgart se pregunta por qué los intelectuales argentinos apelaron a esas ideas para analizar la situación argentina, y responde que fue debido a "la tragedia política (personal y colectiva) que condujo a los regímenes militares que se inauguraron en el Cono Sur entre 1973-1976". ${ }^{25}$ Sin desestimar la importancia decisiva de experiencias como las generadas por el terrorismo de Estado, cabe a su vez preguntarse qué habrían encontrado de nuevo y adecuado en este nuevo enfoque los intelectuales y expertos de la "transición" para interpretar las experiencias personales y colectivas recientes, y qué características específicas ofrecía el modelo en el contexto político argentino. Esto es: si la "crisis" era un concepto conocido aplicado a períodos históricos fácilmente identificables en el sentido común político argentino, si aún era posible recordar caracterizaciones de esos períodos y ciertos momentos como crisis de coyuntura, crisis estructurales o crisis de modernización, ¿qué agregaba sobre la realidad sociopolítica y sobre el fenómeno de las crisis el nuevo modelo? En todo caso, ¿significaba éste una superación conceptual de aquél?

Ciertamente, los conceptos de "transición democrática" o la polaridad autoritarismo/democracia eran una novedad en el lenguaje del análisis político en la Argentina, pero organizar la experiencia en términos dualistas para sustentar y caracterizar "la crisis" argentina era un recurso familiar. ${ }^{26}$ Isidoro Cheresky llamó la atención en 1987 sobre la recurrencia de las tradiciones políticas locales a apelar a las clasificaciones dualistas, tales como nación vs. imperialismo, pueblo vs. oligarquía, obreros vs. burgueses,

25 Lesgart, Cecilia: Usos de la transición a la democracia. Ensayo, ciencia y política en la década del '80, Homo Sapiens Ediciones, Rosario, 2003, pág. 18.

26 Lesgart: Usos de la transición..., págs. 15-16. 
adoptando una posición crítica: si en el pasado dichas polarizaciones podían expresar auténticos conflictos, ahora difícilmente satisfacían las exigencias de un proceso de democratización. Es que si la democracia era concebida como "la lucha secular del pueblo contra sus enemigos" autoritarios, lo único que podía conseguirse con dicho esquema era preservar las ideas políticas dominantes, idealizando al pueblo y sin cuestionar sus tradiciones, ${ }^{27}$ y por ende, lo que de ellas había contribuido a la crisis perenne de la sociedad y la política.

El dualismo en la Argentina puede reconocerse fácilmente en la demonización del adversario político a mediados del siglo XIX, con unitarios y federales, o en la segunda mitad del siglo XX, con peronistas y antiperonistas, y en las concepciones de quienes asumieron la violencia política de la década de 1970. La afirmación de la polaridad antinómica, y el consiguiente extrañamiento entre los dos polos, como si se tratara de dos culturas ajenas entre sí, ha llevado a algunos intelectuales a afirmar una causalidad histórica de los diferentes dualismos políticos generados en el pasado argentino, manteniendo su continuidad. Esta perspectiva conlleva la postulación de una tendencia irreversible de la sociedad y la política, un rasgo atávico o esencial, como sugería el investigador norteamericano Nicholas Shumway en los dos linajes-liberal y nacionalista-que los intelectuales argentinos generaron durante el siglo XIX, antes de la organización del Estado nacional. ${ }^{28}$ Mas si bien es posible reconocer una tendencia a interpretar la vida política en términos dualistas antagónicos, los principios que guían la clasificación dualista, así como los eventos, personajes o instituciones clasificados han ido variando con el tiempo. Por ende, el mentado dualismo argentino constituye una precondición del pasado, un marco interpretativo propiamente nativo con el cual deben tratar los agentes sociales en el presente, y no una esencia de la "condición argentina". El dualismo no se reproduce de manera automática por imposición de la costumbre, sino que representa un desafío, una dificultad que políticos e intelectuales deben enfrentar y resolver en función de sus experiencias, enfoques y exigencias del presente, puesto que las condiciones actuales producen nuevas interpretaciones que, a su vez, obligan a la relectura global del pasado político.

27 Cheresky, Isidoro: "Argentina: régimen político de soberanía compartida", Punto de Vista, 31, Buenos Aires, 1987, págs. 15-22.

28 Neiburg, Federico: Los intelectuales y la invención del peronismo, Alianza editorial, Buenos Aires, 1998, pág. 257. 
Este desafío que representa conciliar experiencias e interpretaciones asumidas con nuevos esquemas referenciales puede seguirse en las reinterpretaciones del pasado político para dar sentido al presente. El mismo año en que la Argentina recuperaba la institucionalidad democrática, el politólogo Marcelo Cavarozzi publicó un libro cuyo título expresaba, justamente, el signo de la dualidad de los nuevos tiempos: Autoritarismo y democracia.$^{29}$ El título era seguido por la periodización "1955-1983", que ponía en evidencia el contexto temporal del cual se ocupaba, y también un punto de inicio a partir del cual tornar inteligible la situación en la que había caído el país en la pasada década. Cavarozzi llevaba al lector a un momento peculiar: el golpe de estado de 1955, denominado por sus protagonistas "Revolución Libertadora", que acabó con el segundo gobierno constitucional del Gral. Juan D. Perón. Dicho de otro modo: el dilema autoritarismodemocracia en que se encontraba atrapada la Argentina en 1983 tenía un origen preciso que se remontaba a veintiocho años antes. De este modo, Cavarozzi no sólo identificaba el origen de la inestabilidad democrática, sino que también ofrecía las claves para reconocer las genealogías de autoritarismo y democracia en la Argentina. El golpe de 1955 se convertía en antecesor de los golpes siguientes, del mismo modo que la "Revolución Libertadora" se transformaba en precursora del PRN. En la misma operación, el gobierno de Perón en 1955 quedaba emparentado con los gobiernos que en los años siguientes cayeron bajo "planteos" o golpes militares (Frondizi en 1962, Illia en 1966 e Isabel Perón en 1976).

Cavarozzi caracterizaba al tiempo pendular de inestabilidad política como "de equilibrio dinámico", esto es, un tiempo durante el cual las fuerzas en pugna habrían arribado a una suerte de imposibilidad de obtener ventajas absolutas o definitivas sobre el adversario. Este tiempo de "equilibrio" se dividía, a su vez, en dos períodos: entre 1955 y 1966, desde la "Libertadora" hasta la caída del radical Arturo Illia, y entre el inmediato ascenso de la "Revolución Argentina" con el Gral. Juan C. Onganía, y el final del PRN. Según Cavarozzi, lo que caracterizó al primer período fue el "fracaso de la semidemocracia" que pretendió operar junto a la proscripción del peronismo. ${ }^{30}$ Sin embargo, el autor admitía que en la naturaleza

29 Cavarozzi, Marcelo: Autoritarismo y democracia (1955-1983), Centro Editor de América Latina, Buenos Aires, 1983.

30 Nos referimos a la proscripción de las imágenes, símbolos, signos, expresiones significativas, doctrinas, artículos y obras artísticas correspondientes o utilizados por los individuos representativos del peronismo, impuesta por el presidente de facto, Pedro Eugenio Aramburu, en 1956. Véase Anales de legislación argentina, XVI-A, 1956, págs. 41-242. 
misma del peronismo se encontraba, también, un relajamiento de los canales político-institucionales debido a la primacía de las relaciones directas "entre el líder y la masa". Ante la "tiranía peronista", los conductores de la "Libertadora" habrían levantado los estandartes de la democracia y el parlamentarismo. Pero al golpe lo sucedieron gobiernos débiles en una época caracterizada por una fórmula política dual: por un lado, un sistema político institucionalizado formado por la alianza entre los partidos políticos antiperonistas y los militares autodenominados "democráticos", y por el otro, una serie de movimientos extra parlamentarios integrados básicamente por el sindicalismo, relacionado con el peronismo proscrito. En modo similar, Liliana de Riz ubicaba lo que consideraba "el problema medular de la Argentina", el peronismo, y la particularidad abierta en 1955 con el partido de las mayorías populares proscrito y con su líder en el exilio. El gran dilema posterior a 1955 para todos los gobiernos, civiles o militares, fue cómo posicionarse ante el peronismo. ${ }^{31}$

Para Cavarozzi el dualismo constituyó, de hecho, una forma efectiva de organización política de la nación, basada después de 1955 en la oposición peronismo/ antiperonismo. Este período tuvo una importancia crucial para entender lo que sucedería después, pues habría sido en el período 1955-1966 que se estableció una nueva forma de hacer política. En primer lugar, se produjo un desfase entre los intereses socioeconómicos y los intereses políticos, puesto que el golpe contra Perón fue llevado a cabo por sectores con intereses económicos diferentes, pero que coincidían políticamente en su deseo de proscribir al peronismo (partidos antiperonistas y militares autodefinidos como "democráticos"). Luego de 1955 este bloque "cada vez más autoritario" se fue fracturando, al no poder arribar a un acuerdo respecto del destino del peronismo (proscripción definitiva o integración) y a la política económica, debatiéndose entre un populismo reformista (expresado por la "Unión Cívica Radical del Pueblo"), el desarrollismo (por la "Unión Cívica Radical Intransigente", que triunfó en las elecciones de 1958) y el liberalismo (expresado por varios partidos conservadores y sectores militares, pero sin base electoral). En segundo lugar, se formó un nuevo actor político con gran autonomía, el movimiento sindical peronista. Si bien las pretensiones de la alianza antiperonista por erradicar o modificar al peronismo fracasaron, en algún modo el movimiento obrero

31 De Riz, Liliana: "Argentina: ni democracia estable ni régimen militar (conjeturas sobre las perspectivas para la democracia)", en Oszlak, Oscar y otros: "Proceso", crisis y transición democrática, Centro Editor de América Latina, Buenos Aires, 1984, págs. 7-28. 
habría cambiado respecto de su perfil y accionar durante la etapa peronista (1946-1955), por estar bajo la tutela del Estado, ya que al convertir al sindicalismo peronista en subversivo y externo al sistema, el establishment fijó las condiciones para cambiarlo en un actor anti-sistema, con la capacidad de lograr golpes de Estado (como en 1966), y de presionar para que los militares en el gobierno abandonen el poder. Finalmente, se produjo el ingreso definitivo de los militares a la arena política, como tutores primero del sistema democrático, y luego de la sociedad y el sistema político. La "Doctrina de Seguridad Nacional" generada en los Estados Unidos, según la cual las Fuerzas Armadas asumían el manejo de los asuntos públicos en función de la seguridad hemisférica, sentaba las bases para el golpe de estado de 1966, con apoyo de liberales (en lo económico) y sindicalistas no verticalistas a Perón. La supremacía militar fue en aumento hasta tomar dominio pleno y distintivo en el período siguiente, la "profundización del autoritarismo" entre 1966 y 1983. El gobierno de Onganía (que derrocara al presidente Radical Arturo Humberto Illia el 28 de junio de 1966) se autopresentó como "fuerte", y con explícitas pretensiones de transformar la sociedad argentina, pero para ello necesitaba caracterizar a la sociedad como "enferma" e incapaz de arribar a consensos. Ello demandaba la aparición de un actor providencial que deviniese en árbitro capaz de mediar y conciliar los intereses opuestos. En este papel las Fuerzas Armadas se internaron en la profundización del control y la represión estatal de la sociedad, y en la imposibilidad de canalizar los reclamos sociales dentro del sistema institucional. Muchos de los espacios extra parlamentarios por los que antes de 1966 había circulado la política de un modo no conflictivo fueron cerrándose, precisamente por la creciente represión. Se generó así un clima de miedo cotidiano que llevó a la destrucción de los sectores productivos y al desmantelamiento cultural, técnico y profesional. Aquí Cavarozzi situaba la emergencia de la violencia social como una respuesta de los espacios no institucionalizados no sólo para continuar existiendo, sino para hacer oír sus reclamos (como en las revueltas populares de 1969, y su mayor exponente, "el Cordobazo"). ${ }^{32}$ De modo similar, de Riz locali-

32 Así se llamó a la huelga general del 30 de mayo de 1969 en la ciudad de Córdoba, corolario de una ola de manifestaciones y luchas callejeras en diferentes ciudades del interior del país; aunque sofocada por la intervención del ejército, puso fin al gobierno de Onganía. Estas revueltas, que expresaban un descontento generacional, se forjaron en alianza con un sector obrero radicalizado. Fue en este proceso que se constituyeron las organizaciones guerrilleras Montoneros (de la Juventud Peronista) y el Ejército Revolucionario del Pueblo (ERP), de orígenes trotskistas, luego guevarista, que protagonizarían la escena política en el primer lustro del decenio siguiente. 
zaba una ruptura crucial en 1966 pues la oposición se separó en "social", por un lado, y "político partidaria", por el otro. Es decir, se generaron grupos sociales movilizados, integrados por trabajadores asalariados y sectores estudiantiles de clase media que hacían política. ${ }^{33}$

Esta respuesta social al proyecto represivo autoritario habría obligado al gobierno militar, ante una inédita situación de "crisis social", a pensar en un retorno a la democracia preparado durante el gobierno del Gral. Alejandro A. Lanusse, mediante el retorno de Perón a la Argentina para reasumir su mandato como presidente, lo que se concretaría en 1973. Según Cavarozzi, Perón compartía con Onganía el diagnóstico del "problema argentino" como "político", pero en lugar de abolirlo pretendió institucionalizarlo. Sin embargo, su gobierno se afirmó en la consolidación de las posiciones ganadas y en el desplazamiento de los adversarios políticos, lo cual no hizo sino minar las fuerzas del régimen democrático. Como consecuencia, la convocatoria del propio gobierno peronista - tras la muerte de Perón en 1974- a las Fuerzas Armadas para llevar a cabo "la lucha contra la subversión" les permitió recuperar la iniciativa política, ya insinuada por los escuadrones de la muerte de la Triple A del gobierno peronista y el ministro José López Rega. ${ }^{34}$

En estas acciones volvía a manifestarse la tensión entre autoritarismo/ democracia que preanunciaba el golpe de estado de 1976. Cavarozzi lo definía como una "revolución burguesa en contra de los burgueses... y de los proletarios" que tenía profundas diferencias con los regímenes anteriores: mientras que en 1955 y 1962 los militares habían impedido que determinados regímenes políticos continuasen en el gobierno, y en 1966 procuraron decididamente instalarse como un gobierno no democrático sostenido por las Fuerzas Armadas, en 1976 el gobierno fue sólo de ellas, y su propósito fue el cambio social radical (erradicar la guerrilla, la política populista y la economía basada en la industria nacional). Para modificar el sistema de relaciones sociales recurría al sistema de libre mercado, que al introducir la competencia de productos extranjeros disminuía la capacidad de sindicatos y empresarios de negociar precios y salarios. En modo semejante, de Riz

33 De Riz: "Argentina: ni democracia...".

34 De febrero de 1975 era el decreto 261 que habilitaba al Comando General del Ejército a “aniquilar el accionar de los elementos subversivos que actúan en la Provincia de Tucumán”. De octubre del mismo año eran los decretos 2770, 2771 y 2772, que otorgaban a las Fuerzas Armadas, Fuerzas de Seguridad y Fuerzas Policiales la potestad de la lucha "contra la subversión" en todo el territorio nacional a través de operaciones militares. 
sostenía que el golpe de 1976 traía un elemento común al de 1966, pero también una diferencia. Si en 1955 y en 1962 el problema había sido cómo impedir que el peronismo llegase a elecciones libres, en 1966 y 1976 los militares sostuvieron que la crisis argentina tenía raíces en la economía y en la sociedad, y en 1976 los militares en el poder postularon como remedio un cambio profundo de la sociedad toda ${ }^{35}$ particularmente en su relación con el Estado. ¿Por qué? Porque dicha relación era "perversa", ya que el Estado era, en su apreciación, fuertemente intervencionista.

Ahora bien, este Estado que en el pasado tuvo tan amplias atribuciones en política económica y asistencial, era intrínsecamente débil ante una sociedad civil fuerte cuyo exceso de poder había sido alcanzado por sus instituciones políticas y corporativas (en especial, el sindicalismo), o por la sobreabundancia de conflictos y demandas ${ }^{36}$ Para transformar a la sociedad civil, el nuevo gobierno apeló no sólo a la represión, sino también a la política económica. Claro que debieron establecer alianzas con determinados sectores de la sociedad civil; fueron los empresarios quienes, según de Riz, no estaban dispuestos a pagar los costos que implicaba la aplicación del modelo, situación que eclosionó en $1981 .{ }^{37} \mathrm{Al}$ propugnar una economía libre del mercado de capitales, se desató necesariamente una selección natural de las empresas más "eficientes". Si tempranamente la gran burguesía agraria fue beneficiada, después fue la perjudicada por la política monetaria, ya que se sostuvo una tasa de devaluación rezagada con respecto a la tasa inflacionaria. Y la reforma financiera sólo llevó a la especulación en medio de una alta inflación. El "momento crítico" fue entre 1980 y principios de 1981, con una sucesión de quiebras bancarias. La brutal transferencia de ingresos del sector asalariado al capital no llegó a favorecer a ningún sector en particular de la burguesía. La "crisis" económica de 1981 llevó al aislamiento de la corporación militar respecto de sus pretendidos aliados sociales, ya que por razones de seguridad no estaban dispuestos a propugnar una política que implicase un alto nivel de desempleo: su objetivo era disciplinar las fuerzas sociales en pugna, no desproteger a la clase obrera ni desmantelar la industria. ${ }^{38}$

35 "Más que nunca se autopercibieron como una corporación militar por encima de la sociedad y, por ende, capaces de hacerse cargo de esa sociedad enferma para imponerle su lógica disciplinaria. El golpe de 1976 fue el más militar de todos". De Riz: "Argentina: ni democracia...", pág. 13.

36 De Riz: "Argentina: ni democracia...", págs. 12-13.

37 Ibídem, pág. 15.

38 Ibídem, pág. 17. 
La debacle económica profundizada por la derrota militar en Malvinas acentuó su propia "crisis" ${ }^{39}$ caracterizada por la debilidad del régimen, la descomposición de la autoridad y la fragmentación interna del gobierno, obligando a los militares a una entrega rápida del poder. ${ }^{40}$ Para Cavarozzi, la coyuntura de 1982-83 sólo era una peor versión de lo mismo que había sucedido en 1975-1976, donde "la sociedad estaba desgobernada", el elenco dirigente desintegrado y la economía fuera de control. Sólo que ahora el camino iba en dirección a la democracia, no al autoritarismo.

Valga esta larga reseña para mostrar que trabajos como los de Cavarozzi y de Riz exhibían el modo en que la contienda entre el autoritarismo y la democracia se habían desplegado en la historia concreta de la Argentina de las últimas tres décadas. Ambos situaban los orígenes de la "inestabilidad democrática" en el golpe de 1955, debido a que la contienda entre peronistas y antiperonistas que la había promovido era central para entender los sucesos, al menos hasta 1973, cuando Perón retornó al poder. Desde este punto de vista, los tiempos inaugurados en 1955 permitían entender por qué se gestaban las intervenciones militares que habían tornado "inestable" a la democracia, las limitaciones a su pleno ejercicio, y la emergencia de un nuevo activismo social y político que buscaría transformar radicalmente las estructuras sociales. Esta situación fue, a su vez, condicionante del nuevo golpe militar de 1976 y de su inédito accionar represivo. Cavarozzi y de Riz veían al PRN como un momento del desarrollo de la contienda entre autoritarismo y democracia, un tiempo singular en el que se intentó llevar a cabo una "última batalla" para curar/transformar definitivamente a la Argentina de sus enfermedades crónicas. Además, y como novedad, los dos autores presentaban al autoritarismo y a la democracia de entonces como descendientes de un sistema de doble filiación, lo que les permitía escapar de la antinomia peronismo/antiperonismo que había dominado el escenario político hasta 1973: aun expresando ciertas dudas respecto del carácter plenamente democrático del peronismo, no podían volver a considerarlo una "tiranía", como lo habían hecho los intelectuales antiperonistas de 1955, e incluso algunos de $1983 .{ }^{41}$

Quizá, la nueva hora exigía que tanto quienes en el pasado habían luchado por la justicia social, como quienes lo habían hecho por las liber-

\footnotetext{
39 Cavarozzi: Autoritarismo...

40 De Riz: "Argentina: ni democracia...".

41 Por ejemplo, Sebreli, Juan José: Los deseos imaginarios del Peronismo, Editorial Legasa, Buenos Aires, 1983.
} 
tades civiles, uniesen sus esfuerzos en una nueva síntesis, como dijo el propio presidente Alfonsín en su discurso de "Convocatoria para una convergencia democrática" a los delegados del Comité Nacional del radicalismo el $1^{\circ}$ de diciembre de 1985. Los golpes militares remontaban su genealogía al 6 de septiembre de 1930, cuando el Gral. José F. Uriburu derrocó al gobierno radical de Hipólito Yrigoyen. ${ }^{42}$ El PRN podía ser interpretado como la expresión culminante del "liberalismo económico", la "antipatria", lo "antinacional", que lidiaba desde los tiempos de la "Organización Nacional" a mediados del siglo XIX, y quizá aún antes, un combate con el polo de la "Patria", con lo "Nacional", ${ }^{43}$ y la naciente "democracia" podía ser inscripta en una genealogía que tenía su origen en la Constitución Nacional de 1853 y en los orígenes de la Argentina como nación, en la introducción del voto universal masculino, secreto y obligatorio por Roque Sáenz Peña en 1912, que permitió la victoria del radicalismo en 1916, pero también en hitos del peronismo como la reforma constitucional de 1949 o la sanción de la ley de 1947 que permitía a las mujeres ejercer su derecho al sufragio. ${ }^{44}$

Todas estas perspectivas eran plausibles, pues descansaban en marcos interpretativos familiares a muchos argentinos. Pero los intelectuales de la "transición democrática" construyeron una peculiar relación con los sistemas de oposiciones pasadas: los analizaban en clave sociológica, política o económica, sin presentarse a sí mismos como continuadores actuales de esas luchas pasadas que los había tenido por partícipes directos unos pocos años atrás. Ciertamente, esto les exigía a algunos, a veces hasta en un tono de extrañeza, interrogarse sobre sus pasiones hoy abandonadas. El compromiso intelectual que debían exhibir era con la "democracia", algo distinto al que podía establecerse con un partido político o con una corporación. Era un asunto de "cultura", de "valores culturales". "Democracia" y "autoritarismo" eran oposiciones profundas, de modo que transformar una "cultura" autoritaria" en otra "democrática" debía permitir entender, a la vez, cómo los viejos compromisos políticos, las luchas que apenas ayer los habían comprometido hasta el riesgo de muerte, podían hoy carecer por completo de sentido.

42 Solari Yrigoyen: “Antidemocracia y democracia...”, pág. 20.

43 Feinman: "Política y verdad...".

44 Landi: "Cultura y política...”, pág. 102. 


\section{Dos culturas}

Tras su pintura de la "deflación del poder" durante el último régimen militar, Cavarozzi consideraba las "posibilidades de la democracia en la Argentina" y concluía que había profundas dificultades para consolidarla, ya que la "cultura política" argentina estaba regida por "valores antidemocráticos"-el "culto a la violencia", la "falta de tolerancia", la "destrucción de los patrones de acuerdo social"-que explicaban por qué el golpe militar de 1976 había gozado de respaldo popular. ${ }^{45}$ La explicación del eterno "fracaso argentino" para consolidar la democracia radicaba, pues, en la debilidad o carencia de una "cultura democrática", a expensas de una vasta "cultura autoritaria".

Por esta vía, Cavarozzi pretendía alcanzar una comprensión más profunda del comportamiento crispado de la política argentina, puesto que una lectura "cultural" permitía trascender los procesos estrictamente económicos y políticos, para poner en primer plano las subjetividades y sus adhesiones valorativas. Por encima de todo sistema institucionalizado o conjunto de normativas, el "autoritarismo" estaba encarnado y naturalizado en las vidas de los sujetos, por lo que la "transición democrática" debía constituir, necesariamente, una "transformación cultural", esto es, una metamorfosis total de las subjetividades. Como sostenía Landi: "La formación de una cultura política democrática no se agota en el consenso a ciertas reglas de elección y de control de los gobiernos, sino también debe expresarse en la vida cotidiana, las relaciones familiares, en las formas de sociabilidad de los argentinos". ${ }^{46} \mathrm{Al}$ mismo tiempo, la perspectiva "cultural" conllevaba otra consecuencia: en cierto modo, responsabilizaba al conjunto social por su destino. En efecto, si el problema del "autoritarismo" era "cultural", no se podía responsabilizar sólo a un sector (los militares) o a un partido (el peronismo), que más bien expresaban valores y creencias colectivos hondamente enraizados en la sociedad. Como vimos, Cheresky ya había planteado la necesidad de no idealizar las tradiciones políticas del pueblo, por su posible contaminación de "autoritarismo".

La apelación a "la cultura" como un medio para interpretar procesos definidos como "políticos" no era nueva en el contexto intelectual argentino. El sociólogo italiano Gino Germani (1911-1979) la había utilizado des-

45 Cavarozzi: Autoritarismo...

46 Landi: "Cultura y política...", pág. 103. 
de su apropiación de la Escuela de Frankfurt (y a través suyo, de Talcott Parsons y la antropología cultural norteamericana), para tratar de entender la adhesión de las masas a regímenes considerados "autoritarios", tales como el fascismo y el nacionalsocialismo en Europa y el peronismo en la Argentina ${ }^{47}$ Pero en la llamada "transición democrática", las referencias invocadas se orientaban a Antonio Gramsci y, muy especialmente, a algunos de sus intérpretes contemporáneos como Raymond Williams. ${ }^{48}$ Para los expertos de la "transición democrática", "cultura" aludía no sólo a un concepto que designaba una de las dimensiones de la vida social, también refería un campo específico de la sociedad moderna en el cual se desenvolvía la acción de los intelectuales. Eran "culturales" las creencias y valores de los argentinos respecto de la autoridad o la libertad, y la producción de artistas y escritores, las críticas sobre esta producción, los medios para difundirlas, y las políticas formuladas desde el Estado para fomentarlas y expandirlas. Aquí nos concentraremos en el primer sentido - como dimensión de la vida social - debido a la importancia crucial que adquirió en los primeros años de la "transición" para comprender el "autoritarismo" y para sentar las condiciones necesarias para convertirlo en "democracia".

Una de las formulaciones en las que es posible encontrar esta perspectiva respecto de "la cultura", así como la impronta de Antonio Gramsci, fue aportada por José Nun en dos trabajos publicados en la revista Punto de Vista (1986, 1987). En el primero, Nun rescataba el enfoque gramsciano del sentido común como un modo de volver la atención a las creencias y valores de los miembros de una sociedad. Su revalorización como crucial a la democracia — en la medida que ésta supone la voluntad popular- ponía en evidencia hasta qué punto el moderno desinterés y falta de información de los ciudadanos por los asuntos públicos, aducidos muchas veces para imputarlos por sus elecciones políticas, era un producto del sistema que, justamente, atentaba contra una auténtica democracia participativa. ${ }^{49}$ Por otra parte, Nun advertía que las "teorías de la transición" que tuviesen

47 Blanco, Alejandro: “Ideología, cultura y política: la 'Escuela de Frankfurt' en la obra de Gino Germani”, en Revista Venezolana de Economía y Ciencias Sociales, vol. 7, n. 3 (sept.-dic.), 2001, págs. 51-77

48 Plotkin, Mariano, y González Leandri, Ricardo: "Estrategias de formación de una elite intelectual en un contexto de redemocratización. El caso de la revista Punto de Vista (1978-1985)", en Plotkin, Mariano, y González Leandri, Ricardo (comps.): Localismo y globalización. Aportes para una historia de los intelectuales en Iberoamérica, CSIC, Madrid, 2001, págs. 217-240.

49 Nun, José: "Elementos para una teoría de la democracia: Gramsci y el sentido común", en Punto de Vista. Revista de Cultura, año IX, N. ${ }^{\circ} 27,1986$, págs. 26-40. 
como modelos de "democracia" a las sociedades occidentales conocidas bajo esa denominación, cometían un error "etnocéntrico" al no tener en cuenta las abismales diferencias que las separaban de las precarias democracias latinoamericanas. En su exhortación, Nun concluía que el desarrollo de una "cultura democrática" no podía realizarse sino a partir de las circunstancias materiales y simbólicas ya existentes, y las tradiciones y creencias locales correspondientes. ${ }^{50}$

A estas precondiciones habían aludido Cavarozzi y Cheresky, sintetizadas en la fórmula de una "cultura autoritaria" en la Argentina anterior al PRN, y en cierto modo como explicación de su llegada y adhesión masiva. Guillermo O'Donnell, por ejemplo, también entendía que el autoritarismo argentino tenía raíces históricas anteriores a 1976, y lo explicaba como un producto del encuentro de las tradiciones políticas del radicalismo y el peronismo con los sectores dominantes de la sociedad. El radicalismo y el peronismo contribuyeron a crear condiciones igualitarias en la sociedad argentina, que permitieron contrapesar una "derecha" que carecía de representación política pero conservaba el poder económico y el prestigio cultural. Sin embargo, esa contribución consistía en acentuar un sistema democrático-institucional frágil, confiando más en la organización corporativa de la sociedad, que poco a poco llevó a un proceso de confrontación cada vez más violento. Esto terminó debilitando a la sociedad, ${ }^{51}$ pues cuando a mediados de los años 1970 estalló la violencia política con su mayor crudeza, gran parte de la población la percibió como "desorden" y "anarquía", ante lo cual no quedaba otro remedio que reclamar "orden". Según O'Donnell, a pesar de que una sociedad que demandaba semejantes valores no parecía necesitar la "inculcación" de valores "autoritarios" por parte del PRN, éste habría percibido que la "subversión" la había infectado, por lo que era urgente una tarea regenerativa. Esta acción del PRN sobre la sociedad también había sido sugerida por Oszlak, para quien el régimen buscaba el "disciplinamiento y reconstitución de los actores sociales y políticos" debido a "la naturaleza indomable de su sociedad civil". ${ }^{52}$

50 Nun, José: "La legitimidad democrática y los parecidos de familia: notas preliminares", en Punto de Vista. Revista de Cultura, año X, N. ${ }^{\circ} 31,1987$, págs. 30-44.

51 O’Donnell, Guillermo: "Democracia en la Argentina: micro y macro", en Oszlak, Oscar (coord.): 'Proceso', crisis y transición democrática/1, CEAL, Buenos Aires, 1987, págs. 13-30.

52 Oszlak, Oscar: "Privatización autoritaria y recreación de la escena pública", en Oszlak, Oscar (coord): 'Proceso', crisis y transición democrática/1, CEAL, Buenos Aires, págs. 31-48. Véase también la "sospecha generalizada" y la "cultura del miedo" en: Villarreal: "Los hilos sociales...", pág. 206. 
O’Donnell marcaba la importancia de este diagnóstico como un modo de implantar un sistema de obediencia y autoridad en la escuela, la familia, el trabajo, en las conductas en la calle o en el aspecto de las personas (ejemplificando con las formas aceptables e inaceptables de vestirse y de peinarse), técnicas que expresaban un proyecto dirigido a despolitizar la sociedad. ${ }^{53}$ Basándose implícitamente en Gramsci y Foucault, y como también lo habían sostenido muchos otros, sostenía que el PRN no había podido ejercer el control sólo a través de sus funcionarios y el aparato represivo, sino que había necesitado que la sociedad se patrullase a sí misma, naturalizase las nuevas disposiciones y se convirtiese en más represiva y autoritaria. ${ }^{54}$ Entonces, el gran peligro que se abría en 1983 era la subsistencia de patrones autoritarios, lo cual exigía tareas de democratización del sistema político y muy especialmente de la vida cotidiana.

En definitiva, la "transición a la democracia", el pasaje del "autoritarismo" a la "democracia", la "democratización" de la sociedad argentina, expresaban un mismo asunto "cultural" o más precisamente un "cambio cultural". ¿Cómo salir de una sociedad presidida por la violencia e ingresar a una sociedad que resolviese sus conflictos mediante "acuerdos"? ¿Cómo pasar a una "cultura" en la que rigiese la "tolerancia" como "valor democrático"? En principio, como señalamos, identificando al "autoritarismo" y sus agentes, y modificándolos mediante la introducción de nuevas normas y valores, potenciando las escasas zonas y agentes "democráticos" que aún contuviera la sociedad civil, posibles ejemplos y vehículos del cambio.

\section{Las rémoras autoritarias y los agentes democráticos de la transición}

Como vimos, Oszlak resumía al autoritarismo en la noción de "privatización autoritaria". El régimen autoritario se había propuesto el disciplinamiento y la reconstitución de los actores sociales y políticos de la Argentina mediante la "redefinición del papel del Estado y el cuestionamiento de la función cumplida por los mecanismos de intermediación política" ${ }^{55} \mathrm{El}$ individuo habría pasado a constituirse en el legítimo defensor de

53 O’Donnell: "Democracia en la Argentina...", pág. 15.

54 Ibídem, pág. 17.

55 Oszlak: "Privatización autoritaria...", pág. 34 
sus intereses, y toda forma de "acción colectiva", toda mediación institucionalizada entre la sociedad y el Estado, perdía legitimidad. La "privatización autoritaria" exigía la "destrucción" de todo aquello que articulara. La sociedad era concebida como un conjunto de múltiples unidades independientes, y el mercado se convertía en la pieza central del proceso de privatización, atomizando a los individuos y promoviendo su mutua competencia, destruyendo sus formas organizativas y redefiniendo sus identidades sociales y políticas. En la Argentina, señalaba Oszlak, el PRN combinó "lo peor de cada sistema", eliminando todo mecanismo de regulación y control de los comportamientos estatales y sociales. Este "vaciamiento de la escena pública" confinó la sociedad a la vida privada.

La "democratización" consistía, entonces, en el proceso inverso a la "privatización" de la sociedad, pues requería de la recreación de la "escena pública". Parafraseando a O'Donnell, ${ }^{56}$ el problema de esta transición era, para Oszlak, que los contextos institucionales debían ser aprehendidos e inventados prácticamente "de la nada", porque la sociedad no había podido conservar sus instituciones fundamentales: los partidos políticos. Por eso, la transición radicaba en recuperar los "mandamientos éticos" que conformarían el marco de la acción política en una sociedad en la que la ausencia de prácticas dogmáticas exigía la explicitación de las normas de conducta. Para que la democratización fuera exitosa, estas normas deberían decantar en la conciencia generada en la "trama profunda de tendencias autoritarias y de poca tolerancia para la disidencia, fruto de una larga historia de prácticas antidemocráticas, reforzadas hasta el horror por el autoritarismo militar" ${ }^{57}$ Por eso, reconocer lo viejo (el autoritarismo) permitiría construir lo nuevo (una sociedad democrática), en la que funcionasen "los mecanismos institucionales para solucionar la crisis sin quebrar el sistema, y producir decisiones allí donde se recurría a la regla autoritaria". ${ }^{58}$ La democracia representativa estaría fundada en la ruptura de esa trama y en la fundación de una nueva relación entre Estado y sociedad basada en la desprivatización-descorporativización-desestatización de la política. Es que el PRN había impuesto un régimen de obediencia y autoridad arraigado en la cotidianeidad, para que la "sociedad se patrullase a sí misma"; así, "no era sólo que el gobierno incitaba sino también —más sutil y poderosamente- el 'permiso' que daba para que se ejerciera el minidespotismo

56 O'Donnell: "Democracia en la Argentina...".

57 De Riz: "Argentina: ni democracia...", pág. 21.

58 Ibídem, pág. 26. 
frente a trabajadores, estudiantes y toda clase de "subordinados". ${ }^{99}$ Para superar esta situación era necesario democratizar también la organización social y la vida cotidiana en su conjunto.

¿Con quiénes se contaba para ello? Si los partidos políticos se encontraban en una encrucijada, la esperanza residía en los "movimientos sociales". Movimientos artísticos como "Teatro Abierto", "Danza Abierta", "Buenos Aires Rock" fueron las primeras expresiones públicas y masivas de oposición al PRN, reivindicando las expresiones de la "cultura popular" como dividida y hasta opuesta a la noción de "cultura" como "bellas artes". Precisamente y en correspondencia con los analistas de los movimientos sociales, Landi encontraba un sitio específico de los intelectuales en general, y del arte en particular. Como la democracia no podía garantizarse por reglas formales, él sugería consolidar la relación entre intelectuales, cultura y vida cotidiana para trazar una ruptura con la intervención estatal basada en la arbitrariedad, las listas negras y la censura. La cultura entendida como arte sería otra avenida hacia una sociedad más íntegra, ética y creativa. ${ }^{60}$

Los intelectuales de la transición, en tanto intérpretes e ingenieros de la nueva democracia, debían identificar los núcleos "puros", "no contaminados", "democráticos", para fundar una nueva sociedad, embistiendo contra los núcleos "impuros", "corrompidos" por el autoritarismo, como las Fuerzas Armadas y de Seguridad, y sus aliados civiles de la derecha. Por definición, aunque no en forma exclusiva, los militares eran autoritarios. Sin embargo, y previo a pronunciarse acerca de los grados de complicidad de otros sectores y agentes de la sociedad civil con el PRN, lo cual podía entrañar ciertos desacuerdos y caer en meras acusaciones, ${ }^{61}$ los científicos sociales se volcaron a la reivindicación positiva de aquéllos a quienes caracterizaban como los auténticos "enemigos" del régimen militar, aquellos grupos que habían peticionado públicamente al régimen de facto; por su empecinada labor, se trataba de los auténticos paladines de la democracia. ${ }^{62}$ Mientras a éstos se les atribuía el poder de desafiar el orden autorita-

59 O’Donnell: “Democracia en la Argentina...”, pág. 18.

60 Landi: "Cultura y política..."

61 Para las disputas verbales entre los intelectuales exiliados en el exterior y aquellos que permanecieron en el país, véase: Sosnowski: Represión y reconstrucción... Sobre acusaciones de "colaboracionistas" a los que permanecieron en el país véase: Bayer, Osvaldo: "Pequeño recordatorio para un país sin memoria”, en Sosnowski: Represión y reconstrucción..., págs. 203-227.

62 Jelin, Elizabeth (comp.): Los nuevos movimientos sociales, CEAL, Buenos Aires, 1985. 
rio, se consideraba que otras organizaciones lo habían perdido por haber sido blanco directo de la represión (las líneas sindicales combativas) o por haberse transformado en cómplices del régimen (la Concentración Nacional de Trabajadores, una escisión de la CGT).

Las organizaciones humanitarias designadas como "organismos de derechos humanos" se convirtieron en el emblema de la pureza anti-autoritaria, y como si se tratara de esencias contagiosas, el contacto con ellas aparecía como la clave para democratizar las organizaciones corporativas invadidas por el autoritarismo, como los sindicatos y los partidos políticos de más larga trayectoria, inexorablemente ligados a algún episodio autoritario del pasado argentino. ${ }^{63}$ Otros agentes de menor importancia eran los agrupamientos sociales caracterizados por alguna actividad o interés colectivo que excedía, como en el caso de los derechos humanos, la clasificación partidaria, ideológica y de clase. Para englobarlos en una misma categoría, los autores retomaron la prolífica literatura sobre los "movimientos sociales", ${ }^{64}$ y se refirieron así a las mujeres, los jóvenes y los vecinos no en tanto adherentes a partidos políticos, sino por inventar canales de expresión propios y diversos, desde los cuales la sociedad argentina habría logrado resistir, con sus grupos de edad, de género y de residencia, el absolutismo de la cultura autoritaria. El "rock nacional", las ollas populares, los grupos feministas eran parte de la esperanza desde donde se podrían construir nuevos patrones realmente democráticos de organización que garantizaran la convivencia pacífica. ${ }^{65}$

Para quienes se ocuparon de ellos ${ }^{66}$ estos movimientos eran confiables por las condiciones que los habían originado. Al obturar los canales

63 Palomino, Héctor: "El movimiento de democratización sindical", en Jelin: Los nuevos movimientos ..., pág. 36-60.

64 Véase: Frederic, Sabina: "De la Plaza al Barrio. Los científicos sociales y la identidad de los Sectores Populares en la transición democrática (1982-1987”, en Rosato, Ana y Balbi, Fernando Alberto (comp.): Representaciones sociales y procesos políticos. Estudios desde la antropología social, Editorial Antropofagia, Buenos Aires, págs. 247-267.

65 Para las manifestaciones intelectuales críticas al régimen, véase: Altamirano, Carlos: "El intelectual en la represión y en la democracia", en Punto de Vista, Revista de Cultura, año IX, N. ${ }^{28}$, 1986, págs. 1-4.

66 García Delgado, Daniel y Juan Silva: "El movimiento vecinal y la democracia: participación y control en el Gran Buenos Aires", en Jelin: Los nuevos movimientos..., pág. 67-90; García Delgado, Daniel R., Errandonea, Alfredo y otros: Los cambios en la sociedad política (1976-1986), Centro Editor de América Latina, Buenos Aires, 1987; González Bombal, Inés: "Protestan los barrios (el murmullo suburbano de la política)", en Jelin: Los nuevos movimientos... pág. 96-116. Sondereguer, María: (1985) "Aparición con vida. El movimiento de Derechos Humanos en la Argentina 1976-1983", en Jelin: Los nuevos movimientos, pág. 7-32. 
tradicionales de ejercicio del poder, típicamente corporativos, la presión de la dictadura había abierto, en forma involuntaria, nuevos canales de expresión de intereses y demandas populares, capaces de limpiar, oxigenar y renovar los canales de la política tradicional. ${ }^{67} \mathrm{La}$ autenticidad, incluyendo la perdurabilidad de la democracia, dependía, para estos autores, del éxito de estos movimientos en imponer métodos de representación autogestivos, autónomos y colectivos arraigados en las bases, no en las elites políticas y gremiales fundadas en el concepto delegativo de la representación democrática, como era el caso de los partidos políticos. Los métodos democráticos de estas organizaciones estaban garantizados, porque el propio régimen autoritario había eliminado los canales corporativos, con lo cual la sociedad civil debió apelar a formas inéditas de participación. ${ }^{68}$ Y puesto que estas agrupaciones se forjaban en las bases populares y en los intersticios de esa sociedad privatizada por el neoliberalismo del PRN, los movimientos sociales habían sido capaces de generar una nueva cultura, esto es, un nuevo cuerpo de sentidos, valores y normas, para sobrevivir en la colectividad y no perecer en el aislamiento y la represión. Esta "cultura de la resistencia" gestada entre 1976 y 1980, los años más sangrientos del terrorismo de estado, constituía para los autores una posible salida a la "crisis de legitimidad" simbolizada y corporizada en el régimen; las "acaloradas discusiones políticas que caracterizaban a los argentinos" fueron reemplazadas por experiencias privadas como el rock, las sociedades de fomento, los derechos humanos y las comunidades eclesiales de base.

Así, en las narrativas de los científicos sociales, los métodos democráticos eran representados en una relación de oposición a los métodos autoritarios, y quienes mejor revelaban esta relación de oposición eran los integrantes del movimiento por los derechos humanos que, epitomizado por las Madres de Plaza de Mayo, concitaban el interés mundial como movimiento por los derechos individuales imprescriptibles, simbolizados en el amor de las madres por sus hijos... desaparecidos. El dualismo caía ante el monismo representado por la unidad biológica indisoluble de la familia humana madre-hijo, que sólo el terror había podido separar ante costos futuros impensables para la sociedad argentina.

67 Villarreal: "Los hilos sociales..."

68 Jelin: Los nuevos movimientos.... 


\section{Post scriptum}

Más allá de todo cuanto se ha dicho y queda por decir en torno al modelo teórico de la transición democrática, hemos querido en estas páginas mostrar cómo algunos de sus puntos nodales se articulaban con la historia de las ideas en la Argentina, y conducían a los intérpretes del modelo por una senda que les resultaba ya familiar. Esta senda era la de la crisis política argentina como una crisis crónica, fundada en una cultura dualista antagónica. Fue este modelo el que dio forma, en la Argentina, a la caracterización de la transición, entendida como un pasaje de un estado rival a otro, oposición producto de un viejo antagonismo que llevó a los argentinos a la eclosión del PRN. Para sostener este modelo de transición, los intelectuales emprendieron varias operaciones: establecieron cuáles eran las dos partes contendientes - autoritarismo y democracia-, les asignaron un valor —negativo y positivo, respectivamente-, y esbozaron las condiciones para el triunfo de un polo sobre el otro para emerger definitivamente de la lógica pendular en la que se movía la crónica crisis argentina. La concepción subyacente en las intervenciones de estos científicos sociales consistió, pues, en un dualismo antagónico compuesto por dos culturas irreconciliables de la política argentina que condujeron a la crisis final, cuyos dos ingredientes necesarios fueron el terrorismo estatal y la economía neoliberal.

Si bien no buscamos que los autores examinados fueran representativos del período tratado, creemos junto con Lesgart que su vocalidad representaba el compromiso de parte de los intelectuales argentinos, muchos de ellos volviendo del exilio, con el proceso político posible aunque difícil en la Argentina. El marco interpretativo del modelo de y para la transición democrática permeó el medio universitario de todo el país, y la enorme producción a la que se volcaron sus intérpretes se vio amplificada notablemente por el evento sin precedentes del Juicio a las Juntas Militares (1985), y las posteriores reacciones castrenses de 1987, 1988 y 1990, que amenazaron con volver la pesa del péndulo al polo autoritario. La amenaza residía, precisamente, en que el futuro fuera una reedición del pasado, y su superación consistía en forjar un futuro absolutamente distinto al pasado.

¿Cuáles eran los alcances del modelo? La identificación coyuntural del paso a dar, la claridad de objetivos teórico-prácticos y la delimitación de los campos. En continuidad con el pasado, el modelo debía seguir inscripto en la lógica del enemigo, ya que la propuesta era consolidarse en el 
poder para salir definitivamente de la crisis a la que había conducido el endémico autoritarismo argentino. Sin embargo, dicha inscripción caía necesariamente en una simplificación de la política y la sociedad, connotada moralmente según períodos, filiaciones y actores. El sesgo culturalista implícito en la caracterización del autoritarismo argentino alcanzó a todo el espectro social y político de manera que la fuente alternativa - democrática- debía venir desde "afuera", o al menos, desde "afuera" del polo autoritario. Por eso, estos intelectuales aparecían extrañados de su propio pasado político, y de la lógica que había acompañado a sus opciones pasadas. También, por eso necesitaban generar actores internos a la Argentina, de probada calidad democrática, si es que la nueva etapa estaba llamada a durar. Pero con este procedimiento analítico no hacían más que confirmar un sistema clasificatorio establecido a priori que, a la hora de sugerir preguntas de investigación, debía desembocar más en una profecía autocumplida que en nuevos objetos de conocimiento.

La perspectiva dualista con que los científicos sociales se erigían en expertos sobre la crisis permitía abordar tan sólo como recaídas o retrocesos autoritarios lo que era responsabilidad o "decisión" política de los sectores involucrados, impidiendo apreciar, por ejemplo, la enormidad de matices y contradicciones en cada acto, cada evento, cada sector. Las interpretaciones nativas de las que hablaba Geertz, y que, en efecto, tanto había tenido en cuenta Gramsci en su llamado a detectar los núcleos de buen sentido que despuntaban en el sentido común, debían ceder ante la moralización de lo sociopolítico y a la división del panorama argentino en hebras democráticas y listones autoritarios. La fórmula laudatoria sobre los "héroes de Malvinas" con que el presidente Alfonsín culminó la primera de cuatro sublevaciones militares al orden institucional, para referirse a los sublevados de Semana Santa (1987); la finalización de dichas sublevaciones con el encierro de uno de sus cabecillas y el simultáneo indulto presidencial de Carlos S. Menem en la Navidad de 1990 a los comandantes presos; el férreo orden democrático que actuó de sostén de la privatización de las empresas públicas y a la flexibilización de la legislación laboral, que condujo entre 1989 y 2001 a un nivel de desocupación, hambre y miseria inéditos en la sociedad argentina, son algunos hitos de un decurso que en nada se parecería a un ordenamiento dualista, y que contaminó de síndrome autoritario hasta al más pintado demócrata.

El "modelo de" la transición tuvo así interesantes efectos en la institución de temas posibles de investigación. La detección del autoritarismo 
fue paralela al análisis de los protagonistas "democráticos", segregados de otros sectores sindicados como autoritarios, y que fueron o bien condenados de antemano, o bien ignorados por la literatura. Las organizaciones defensoras de derechos humanos y los grupos reconocidos como "movimientos sociales" en tanto reivindicativos de derechos fundamentales estuvieron en el centro de la escena sociológica, pluralizando los actores objeto de estudio. Entre tanto, los quiebres "autoritarios" en su interior quedaron fuera de la atención. Las huellas del dualismo encumbrado como monismo final se adivinaban en procesos sociales que jamás estuvieron regidos por actores sólo democráticos ni sólo autoritarios. Las contaminaciones recíprocas en el decurso del servicio de psiquiatría del hospital Evita, más conocido como "el Lanús", fueron largamente desestimadas para concluir en versiones más heroicas y por ello, necesariamente, más esquemáticas. El caso de la guerra de Malvinas, que apenas comenzó a entrar en la investigación empírica a fines de los años 1990, es por demás revelador: ni los ex soldados fueron analizados como partícipes de un "movimiento social", ni el respaldo popular a la causa de Malvinas en 1982 fue caracterizado como algo más que objeto y suceso de la manipulación política ejercida por la Junta militar. ${ }^{69}$ Siendo uno de los dos legados políticos más notorios del PRN, es notable que ni los ex soldados hayan logrado aunar sus esfuerzos con las organizaciones humanitarias, ni los trabajos sobre derechos humanos hayan podido entender el lugar específico de los únicos civiles argentinos que participaron en una guerra regular en el siglo XX, a instancias de toda la sociedad argentina.

Como "modelo para" actuar en la realidad, la transición a la democracia inundó todas las esferas posibles de sentido relativas a la vida académica y universitaria de las humanidades y las ciencias sociales. Si los conductores del PRN atribuían al mal subversivo la distorsión de la sociedad toda, y por lo tanto trataron de re-instruir o "reorganizar" a los argentinos, ahora se trataba de insuflar la cultura democrática en una sociedad enferma de autoritarismo. Esta mirada, tan holística como el mismo concepto de "cultura", renovó los estudios empíricos desde múltiples perspectivas y relaciones. Sin embargo, su margen se fue revelando estrecho en la medida que los objetos y los resultados de las investigaciones debían subordinarse al fortalecimiento de la agenda democrática, más que indagar el autoritarismo

69 Visacovsky: El Lanús... ; Guber, Rosana: ¿Por qué Malvinas?, Fondo de Cultura Económica, Buenos Aires, 2001; Guber, Rosana: De chicos a veteranos. Memorias Argentinas de la guerra de Malvinas, Editorial Antropofagia, Buenos Aires, 2004. 
de los democráticos, y alguno que otro quiebre democrático entre los autoritarios. La caracterización de la crisis de 1982 y de todas las anteriores como un modelo de transición democrática basada en la noción de cultura política dualista, fue un puente para interpretar y resolver la crisis argentina entendida como un dilema pendular. Pero en el cruce de dicho puente, el modelo reveló también los alcances y limitaciones de la noción que los intelectuales trazaron de la crisis, para conducir, ¿acaso esta vez sí?, a una reorganización cultural de la política y la sociedad. Por lo demás, la crisis como objeto y como concepto siguió acaeciendo a los argentinos. 